\title{
Epithelial surfaces of the trachea and principal bronchi in the rat
}

\author{
I V A N A LEXANDER,B.C. R I T CHIE, \\ J.E. MALONEY, and C.R. HUN T ER \\ Departments of Anatomy and Medicine, Monash University, Baker Institute, Alfred Hospital \\ and School of Biological Sciences, La Trobe University, Melbourne, Victoria, Australia
}

\begin{abstract}
Alexander, I., Ritchie, B. C., Maloney, J. E., and Hunter, C. R. (1975). Thorax, 30, 171-177. Epithelial surfaces of the trachea and principal bronchi in the rat. The epithelial surfaces in the trachea and principal bronchi of healthy rats were examined by scanning electron microscopy. A system of four cell types, ciliated, microvillous, brush, and goblet cells, in this order of frequency, were found and intermediate type cells were not seen. An extensive area of the surface examined was covered by densely ciliated epithelium. The presence of other cell types beneath the cilia was confirmed by transmission electron microscopy.

Areas up to $1 \mathrm{~mm}$ in diameter and randomly distributed were observed where microvillous cells predominated and only occasional ciliated cells were found. Most ciliated cells in these areas were adjacent to glandular openings or goblet cells.

The larger microvilli of the brush cells were arranged in a coronal configuration elucidated by the scanning electron microscope.

Preparatory techniques recently introduced for the examination of soft tissue in the scanning electron microscope facilitated the confirmation of cell types present and the microarchitecture of the epithelial surface.
\end{abstract}

Scanning and transmission electron microscopy was used to demonstrate the structure of the tracheal and principal bronchial epithelial surfaces in the rat. Cell types present, their relationship to each other, and their pattern of distribution were studied.

Scanning electron microscopy, due to the versatility in its range of magnification and great depth of focus, was particularly useful in demonstrating the microarchitecture of epithelial surfaces. Recently introduced techniques of soft tissue preparation for the vacuum of the scanning electron microscope were instrumental in depicting the tissues examined.

Tissue surfaces consisted of four distinct varieties of cell types, ciliated cells outnumbering the other three, in decreasing frequency, microvillous, brush, and goblet cells. A number of areas of up to $1 \mathrm{~mm}$ in diameter were found where sheets of microvillous cells formed the epithelial surface, relieved only occasionally by one of the other three cell types. The same surface pattern was found throughout the entire tracheobronchial area examined.

\section{MATERIAL AND METHODS}

Healthy 5-month-old male and female rats of the Sprague Dawley strain, 270-370 $\mathrm{g}$ in weight, kept under standard laboratory conditions, fed on a diet of Gro-Chick Ration (Clark King and Co. Pty. Ltd., Melbourne) containing approximately 1800 IU of vitamin A per kg (Harris et al., 1972) were injected intraperitoneally with heparin (Heparin injection BP, $5000 \mathrm{IU} / \mathrm{kg}$ body weight). They were anaesthetized one hour later with intraperitoneal sodium pentobarbitone $(50 \mathrm{mg} / \mathrm{kg}$ body weight), their chests were opened, and the aorta was cannulated through the left ventricle; $5 \%$ phosphate buffered glutaraldehyde (Sjöstrand, 1967) was injected into the aorta by gravity at approximately the mean arterial pressure $\left(120 \mathrm{~cm}\right.$ fixative). Fixative was kept at $4^{\circ} \mathrm{C}$ and injected at the rate of about $500 \mathrm{ml} / \mathrm{kg}$ body weight per minute for 20 minutes. The trachea and main bronchi were removed from each animal in toto. Specimens were then divided longitudinally and the resultant pieces were separated transversely into five portions. Fixation was continued in the same buffered glutaraldehyde overnight at $4^{\circ} \mathrm{C}$. Washing in buffer and post-fixation in $2 \%$ osmium tetroxide for one hour at $4^{\circ} \mathrm{C}$ and dehydration in graded alcohol solutions followed. 
Tissues were then transferred into an epoxy propane-Araldite mixture and finally embedded in Araldite (Glauert and Glauert, 1958; Alexander et al., 1973). After two hours at room temperature they were polymerized for 30 minutes at $60^{\circ} \mathrm{C}$, soaked for 10 minutes in acetone, and scoured with it until all surfaces presented a mat appearance, and finally polymerized at $60^{\circ} \mathrm{C}$ for 48 hours. Specimens were then mounted on metal stubs with a plasticized nitrocellulose solution (Colorless Cutex Spillproof Polish, Cheseborough-Ponds International Ltd., Clayton, Victoria). The stubs bearing the specimens were positioned at an angle of $45^{\circ}$ to an evaporation source and rotated in vacuo while a conducting layer of gold was deposited on all exposed surfaces. The thickness of the layer was controlled by matching the colour of a similarly exposed tile to a standard. Transmission electron microscopic examination of similarly treated material, embedded and sectioned appropriately, showed the thickness of the gold layer to be $20 \mathrm{~nm}$. The bases of the specimens were painted with a colloidal silver solution (DAG, 915-Acheson Colloids Company, Prince Rock, Plymouth, England).

Specimens were examined in various scanning electron microscopes at an accelerating voltage of $20 \mathrm{keV}$. Micrographs were taken on Polaroid series 42 and 55 films (Polaroid Land Co.).

For control purposes selected tissues were handled separately from the stage of Araldite embedding, polymerized in blocks, and thin sectioned. Sections were mounted on uncoated grids, stained with uranyl acetate (Huxley and Zubay, 1961) and lead citrate (Reynolds, 1963), and examined in various transmission electron microscopes at 75 and $80 \mathrm{keV}$.

\section{RESULTS}

Four cell types and four cell types only, i.e., ciliated, microvillous, brush, and goblet cells, make up the epithelial surfaces of the trachea and bronchi in that order of frequency.

The largest area of the tissue surfaces showed nothing but a regular array of cilia obscuring cell surfaces (Fig. 1). Cilia were relatively large cylindrical structures (6 $\mu \mathrm{m}$ long and $0.2 \mu \mathrm{m}$ in diameter) and they were interposed between the scanning beam and the cell surfaces.

The scanning electron microscopic appearance of the ciliated cells differed in no way from the description given by Barber and Boyde (1968). The transmission electron microscopic image of this part of the cell was first described two decades ago in the classic paper of Fawcett and Porter (1954). The extracellular parts of the cilia possessed nine doublets of peripheral microtubules. These surrounded a central pair of filaments making up the well-known axoneme. This pattern is almost invariable (Fig. 6).
Areas were found in the tissues examined where ciliated cells were almost completely absent. In these tracts microvillous cells outnumbered all등 others (Fig. 5). Here, as in all other parts of the tissues examined, every cell type was represented $\overrightarrow{\mathbb{\Phi}}$ but in different proportions. The microvillous cells occasionally formed sheets of cell surfaces exclud-ळ ing all others (Fig. 2). The transmission electron $\vec{\circ}$ micrograph (Fig. 11) shows microvillous cells and $\overrightarrow{\vec{H}}$ a brush cell intermingled with ciliated cells.

All the cell apices in the tracheobronchial tract examined were bordered by straight lines of microvilli (Figs 3 and 6). Microvilli of the respiratory surface resembled the brush border of thein intestinal epithelium (Ito, 1965; Revel and Ito, $\vec{v}$ 1967). Microvilli are covered with a cell mem- $\overrightarrow{0}$ brane and have a core of cytoplasm; this is con-음 tiguous with the cytoplasm of the cell itself. In the cores the cytoplasm is dense and filamentouso (Fig. 12). Filaments extend into the terminal web of the cell and outside the cell membrane into a $\vec{\theta}$ filamentous halo, the glycocalyx. Microvilli are $v$ $0.3 \mu \mathrm{m}$ in length and approximately $0.1 \mu \mathrm{m}$ in width on all types of cells (Fig. 6). In scanning micrographs the microvilli are about $0.25 \mu \mathrm{m}$ in

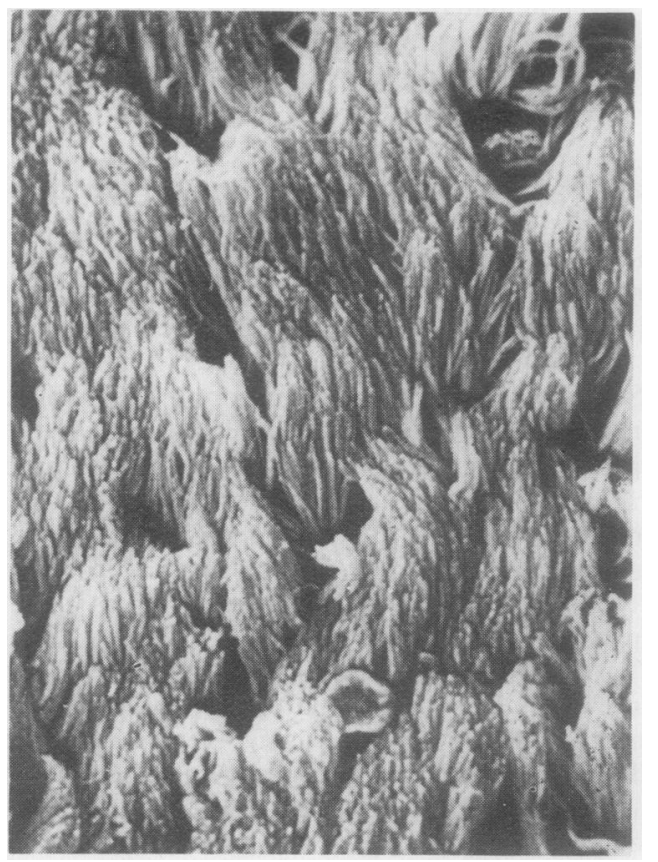

FIG. 1. Array of cilia covering the largest area of the tissues examined. Their dense mass prevents the $\stackrel{\mathbb{\Phi}}{\mathbb{D}}$ scanning beam from depicting all underlying struc-물 tures (approx. $\times 1000$ ). 


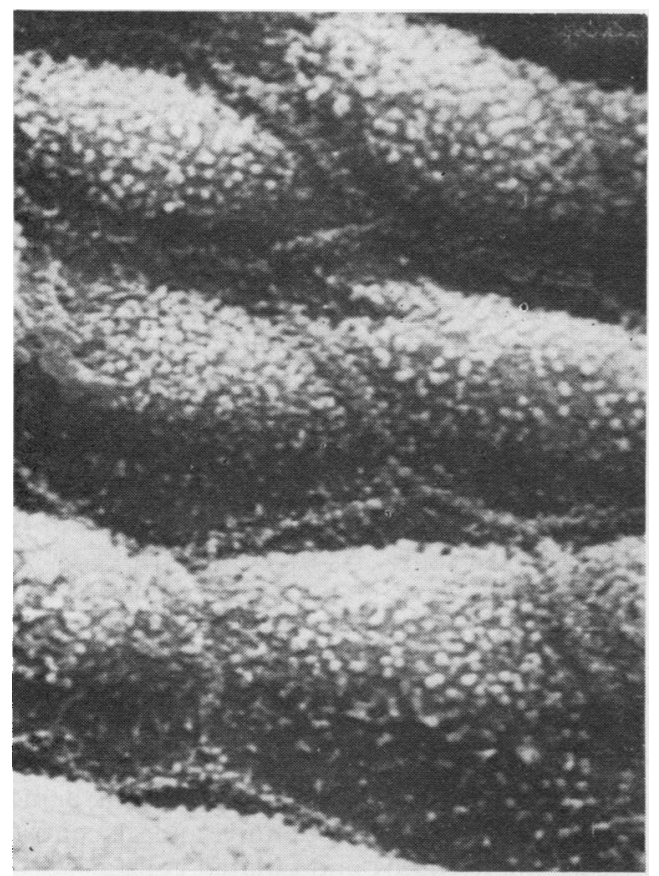

FIG. 2. SEM of microvillous cells from one of the major bronchi. Central elevations bear most of the microvilli. A pices of the cells are clearly demarcated (approx. $\times 5000)$.

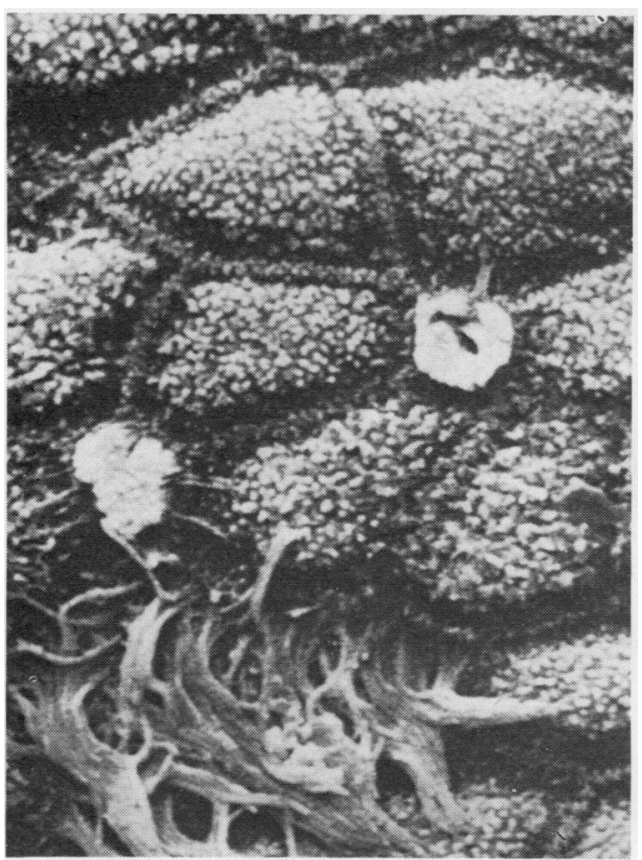

FIG. 4. SEM of microvillous area in the lower part of a principal bronchus relieved by two brush cells and a ciliated cell (approx. $\times 800$ ).

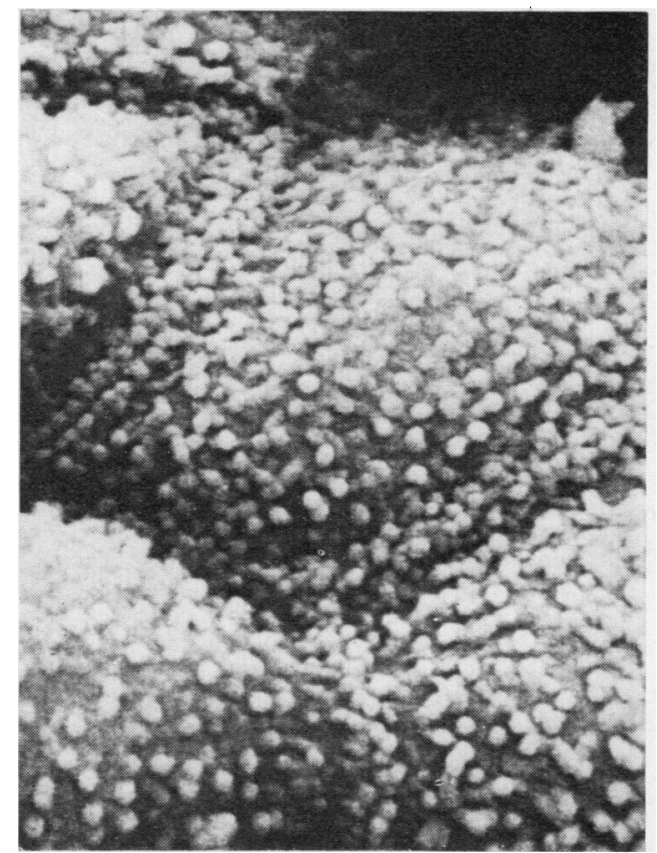

FIG. 3. SEM of microvillous cells in the trachea. A double row of microvilli separates the cellular apices (approx. $\times 7000$ ).

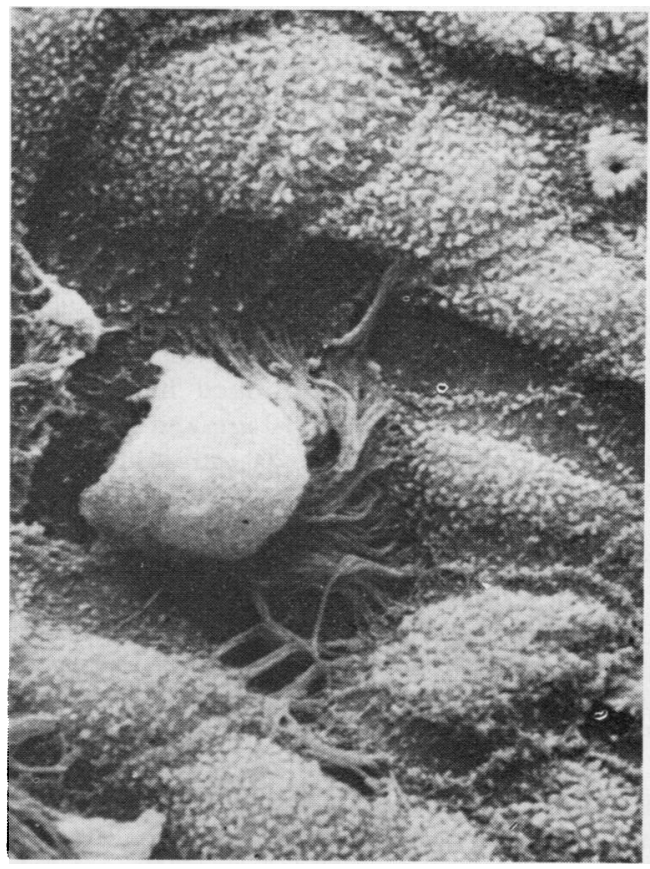

FIG. 5. SEM of microvillous area near the carina. The goblet cell on the lower left is bordered by cilia. A small brush cell is visible in the upper right part of the micrograph (approx. $\times 1000$ ). 


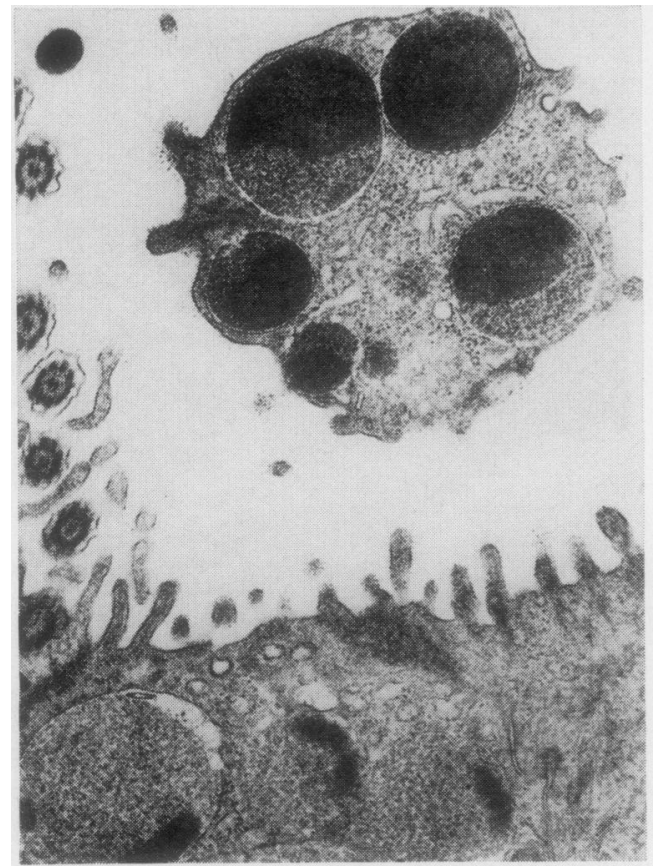

FIG. 6. TEM view of microvillous and ciliated cell apices. The detached part is due to skewed sectioning and emphasizes the central elevations of the microvillous cell. Granules show characteristic demilunes. Microvilli are seen at the junction of all cells. Ciliated patterns are apparent on the left side of the micrograph (approx. $\times 15,000$ ).

width (Fig. 9) probably due to the inclusion of the glycocalyces in the sample (Ceccarelli, Clementi, and De Giuli, 1969). Microvillous cells found throughout the tissues examined had an apical diameter of approximately $10 \mu \mathrm{m}$ and were columnar, being approximately $20 \mu \mathrm{m}$ in length and $10 \mu \mathrm{m}$ in diameter.

Tracts of up to $1 \mathrm{~mm}$ in diameter were found almost completely covered by these cells. Tracts of this description were relieved by relatively few of the other types of cells. The transmission electron microscopic appearance of microvillous cells was similar to that of the 'mucous' cell of Rhodin (1959).

Membrane-bound granules of varying appearance in accordance with their location in the cell were numerous. Near the cell centre they were $0.5 \mu \mathrm{m}$ in diameter, containing small round dark bodies of approximately $30 \mathrm{~nm}$ in diameter, superimposed on a granular lighter background (Fig. 7). Nearer the apex the granules were approximately
$1 \mu \mathrm{m}$ in diameter with alternating darker and lighter demilunes (Fig. 6).

Brush cells were seen with equal frequency inc the ciliated and microvillous areas. Their apices were commonly pentagonal and each side measured some $4 \mu \mathrm{m}$ in length (Fig. 9). Approxi mately 100 very large microvilli, nearly $2 \mu$ min long and $0.2 \mu \mathrm{m}$ in diameter (Figs 9 and 10) $\overrightarrow{0}$ occupied the centre of these cells' apices and weregathered into a corona surrounding a centra $\vec{\omega}$ opening of $1 \mu \mathrm{m}$ in diameter. Their transmissions views (Fig. 10) were in accordance with similare cells described by Silva (1966), Meyrick and Reiфit (1968), and Luciano, Reale, and Ruska (1969). î

Goblet cells were sparse. Each goblet cell seen in the microvillous areas was marked by a single adjacent ciliated cell (Fig. 5). Transmission views did not differ from those of Rhodin and Dalhamm (1956), Rhodin (1959), and Cireli (1966).

There were few glandular openings or goble cells (Fig. 8). The one referred to and depictedo showed its funnel-like opening and its entrancer lined by microvillous and ciliated cells.

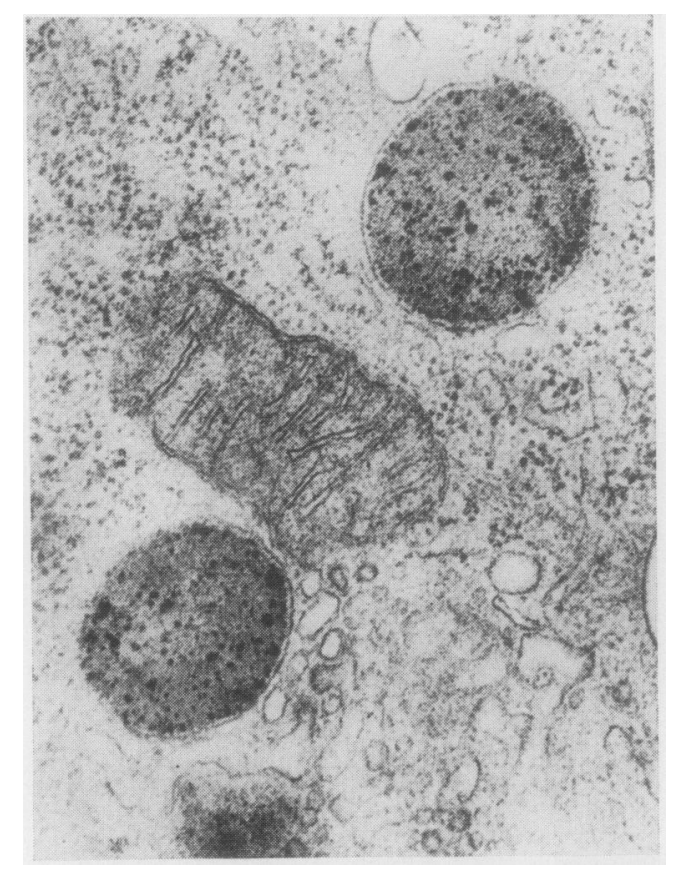

FIG. 7. TEM of supranuclear region of microvillou cell. A mitachrondrion is seen between two character istically speckled granules in the immediate vicinit $\mathbb{D}$ of the Golgi apparatus $(\times 16,000)$. 


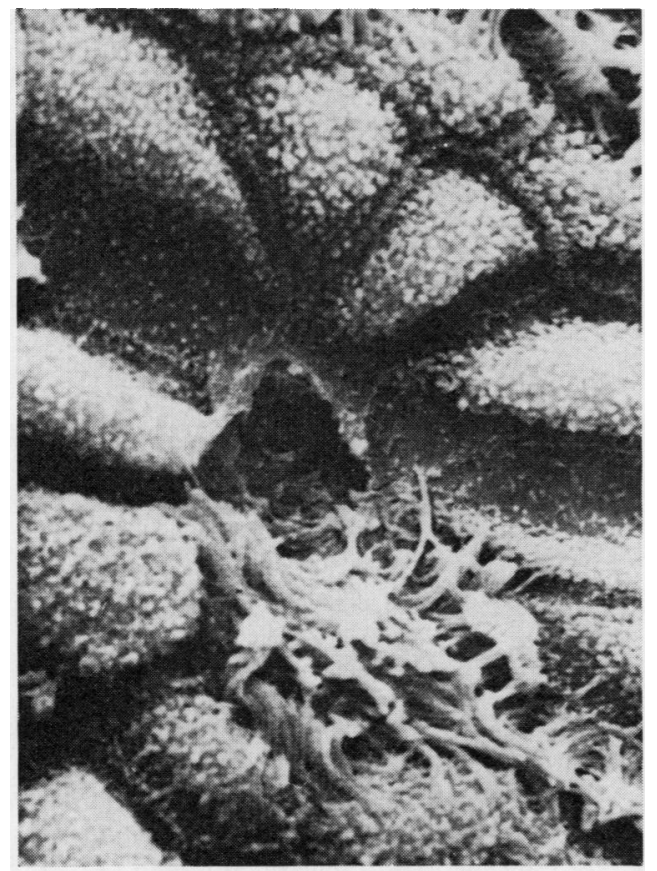

FIG. 8. SEM of glandular opening funnelling out into the tissue near the first ring of the trachea. It is in a microvillous area. A ciliated cell is visible and cilia reach up from the glandular orifice (approx. $\times 1000)$.

\section{DISCUSSION}

Rhodin and Dalhamn (1956) have described ciliated, goblet, brush, and 'basal' cells. More advanced techniques utilized by Rhodin (1963) established that the epithelial covering is made up of four cell types. Intermediate cells were described similar to, but not identical with, the above four, and it was stated that the tracheal and principal bronchial surfaces were uniform. Blenkinsopp (1967), using light microscopy only, identified four clearly recognizable superficial cell types.

Microvillous cells discussed above were referred to by Alexander, Ritchie, and Maloney (1971) as 'collicular'. A similar cell type was termed 'nonciliated' by Hansell and Moretti (1969) in their transmission electron microscopic description of the mouse trachea.

Vitamin A deficiency, possibly responsible for areas lacking cilia, was prevented by adequate amounts of this substance being incorporated in the pellets fed to the experimental animals (Harris et al., 1972).

The plastic infusion and scouring techniques employed here and described previously (Alexander et al., 1971 and 1973) had their origin in an idea of Barber and Boyde (1968), who suggested, in a scanning electron microscopic study of cilia, that tissues might be fixed and embedded as for transmission electron microscopy and then, using a solvent, the excessive embeddent eroded away so leaving just the surface. The sucessful application of this idea demonstrated the large microvillous areas and the configuration of the brush cell apex.

The few glandular openings found could perhaps be explained by the large number of secretory granules of variable electron densities seen in every ceil of the tissues examined (Fig. 11). It is interesting in this regard to compare the similar composition of the apical granules of the microvillous cells found in the tracheobronchial surfaces in the rat (Fig. 6) and the ones seen by Meyrick and Reid (1970) in human bronchial glandular tissue, which may account for the scarcity of these glands in the rat, similar granules being discharged from surface cells.

Large tracts of nonciliated areas seem not to interfere with the flow of mucus in healthy animals - this may be due to the microvilli being able to induce movement in the deeper, relatively non-viscous layer of the mucus (Friedmann and Bird, 1971). It is interesting to note that both goblet cells and glandular openings were associated with at least one adjacent ciliated cell, even in the microvillous areas (Figs 5 and 8).

Scanning electron microscopy confirmed by transmission electron microscopy has shown that the highly sophisticated and structured microarchitecture of the rats' tracheobronchial surface consists of a mixture of four cell types. These are all distinct, and it is now possible to state that intermediate or 'basal' cells are not ordinarily found to exist on the surface of healthy animals. The regularity of configuration has shown the importance of electron optical investigation of epithelial surfaces.

This work was supported by the Australian Tobacco Research Foundation.

The help and advice of Professors G. C. Schofield and A. B. Wardrop and the technical help of Mrs. V. Case, Miss M. L. Exelby, Mrs. M. Rose, and Miss M. L. Coyne are gratefully acknowledged.

Professor I. W. B. Thornton kindly read the manuscript. 


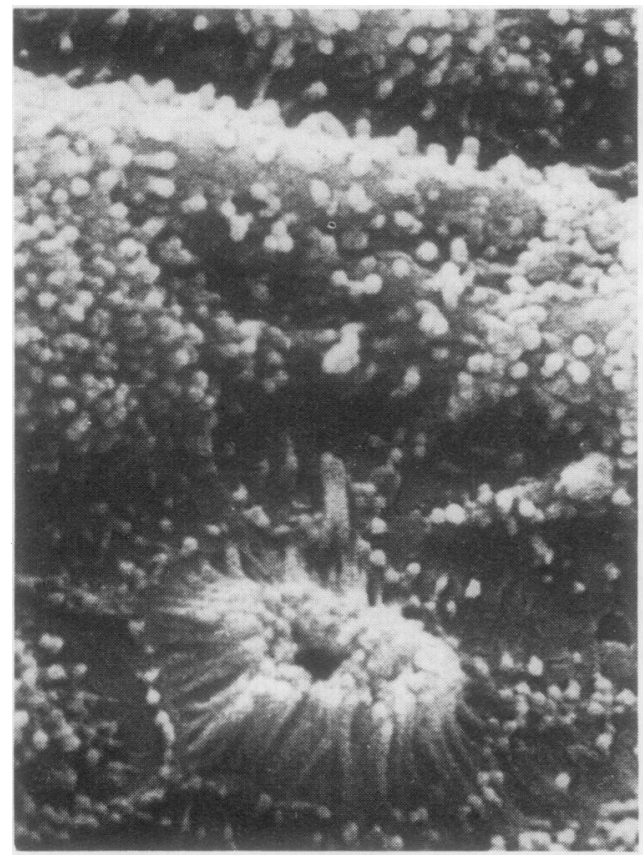

FIG. 9. SEM of microvillous cells surrounding a brush cell. The long microvilli are seen in their distinctive position with the central opening. Cell borders are marked by straight lines of microvilli (approx. $\times 1000)$.

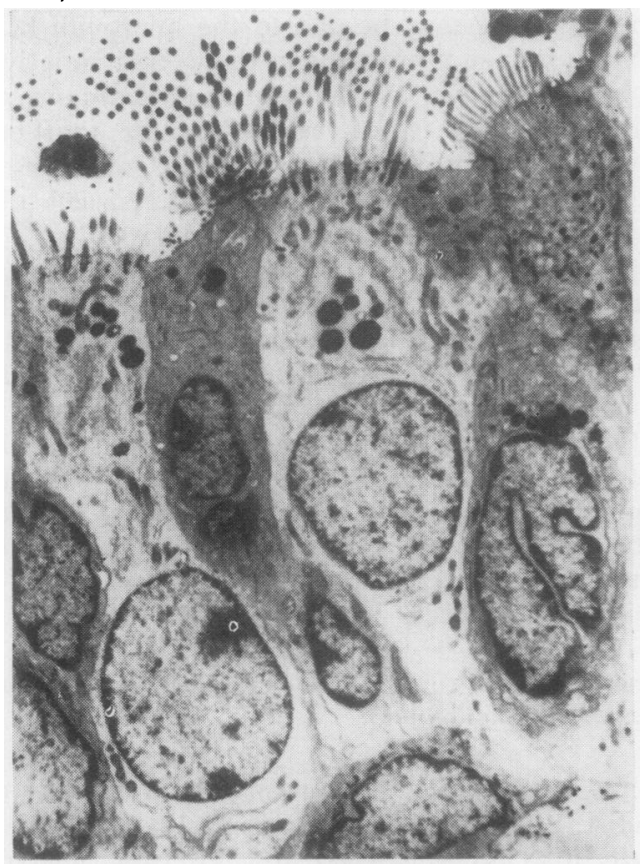

FIG. 11. Longitudinal section of principal bronchial epithelium shown by TEM. Microvillous and ciliated cells alternate on the surface. A brush cell is seen in the upper right-hand portion of the micrograph (approx. $\times 4000)$.

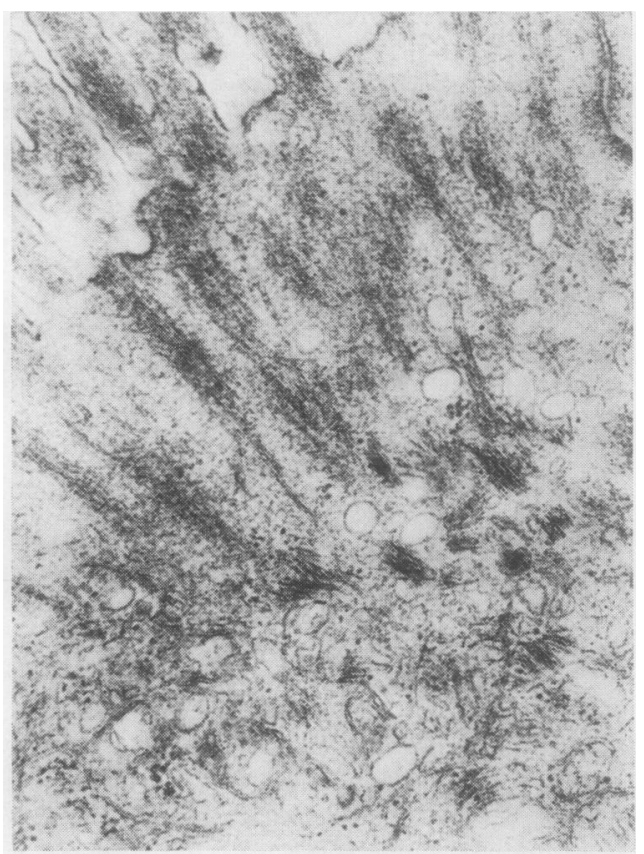

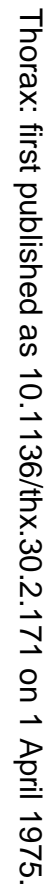

FIG. 10. TEM of apical region, brush cell. The long microvilli have a central core of fine filaments exten ing into the cells web in individual bundles $(\times 21,0000$

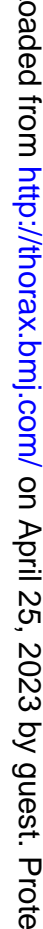

FIG. 12. TEM of surface of microvillous cells. Micr villi are seen in longitudinal section. Their filamento core is connected with the terminal web of the celts below and the glycocalyces surrounding the microvilli $(\times 30,000)$. 


\section{REFERENCES}

Alexander, I. G. S., Capicchiano, P. M., Ritchie, B. C., and Maloney, J. E. (1973). Plastic embedding and surface erosion techniques in soft tissue scanning electron microscopy. Journal of Microscopy, 99, 69.

Ritchie, B. C., and Maloney, J. E. (1971). Scanning electron microscopy of respiratory tissues in the rat. Journal of Anatomy, 110, 491.

Barber, V. C. and Boyde, A. (1968). Scanning electron microscopic studies of cilia. Zeitschrift für Zellforschung und mikroskopische Anatomie, 84, 269.

Blenkinsopp, W. K. (1967). Proliferation of respiratory tract epithelium in the rat. Experimental Cell Research, 46, 144.

Ceccarelli, B., Clementi, F., and DeGiuli, C. (1969). Aspetto di alcune mucose dell'apparato digerente al microscopio elettronico a scansione. Bollettino della Società Italiano di Biologia Sperimentale, 45, 646.

Cireli, E. (1966). Elektronenmikroskopische Analyse der prä- und postnatalen Differenzierung des Epithels der oberen Luftwege der Ratte. Zeitschrift für mikroskopische-anatomische Forschung, 74, 132.

Fawcett, D. W. and Porter K. R. (1954). Study of the fine structure of ciliated epithelia. Journal of Morphology, 94, 221.

Friedmann, I. and Bird, E. S. (1971). Ciliary structure, ciliogenesis, microvilli. (Electron microscopy of the upper respiratory tract). Laryngoscope, 81, 1852.

Glauert, A. M. and Glauert, R. H. (1958). Araldite as an embedding medium for electron microscopy. Journal of Biophysical and Biochemical Cytology, 4, 191.

Hansell, M. M. and Moretti, R. L. (1969). Ultrastructure of the mouse tracheal epithelium. Journal of Morphology, 128, 159.

Harris, C. C., Sporn, M. B., Kaufman, D. G., Smith, J. M., Jackson, F. E., and Saffioti, U., (1972). Histogenesis of squamous metaplasia in the hamster tracheal epithelium caused by vitamin $A$ deficiency or benzo(a)pyrene-ferric oxide. Journal of the National Cancer Institute, 48, 743.
Huxley, H. E. and Zubay, G. (1961). Preferential staining of nucleic acid-containing structures for electron microscopy. Journal of Biophysical and Biochemical Cytology, 11, 273.

Ito, S. (1965). The enteric surface coat on cat intestinal microvilli. Journal of Cell Biology (supplement of Journal of Biophysical and Biochemical Cytology) 27, 475.

Luciano, L., Reale, E., and Ruska, H. (1969). Bürstenzellen im Alveolarepithel der Rattenlunge. Zeitschrift für Zellforschung und mikroskopische Anatomie, 95, 198.

Meyrick, B. and Reid, L. (1968). The alveolar brush cell in rat lung - a third pneumonocyte. Journal of Ultrastructure Research, 23, 71. and - (1970). Ultrastructure of cells in the human bronchial submucosal glands. Journal of Anatomy, 107, 281.

Revel, J. P. and Ito, S. (1967). Electron microscopic studies of the surface components of animal cells. In The Specificity of Cell Surfaces, p. 211. Prentice-Hall, New Jersey.

Reynolds, E. S. (1963). The use of lead citrate at high $\mathrm{pH}$ as an electron-opaque stain in electron microscopy. Journal of Cell Biology, 17, 208.

Rhodin, J. A. (1959). Ultrastructure of the tracheal ciliated mucosa in rat and man. Annals of Otology, Rhinology and Laryngology, 68, 964.

(1963). An Atlas of Ultrastructure. Saunders, Philadelphia.

and Dalhamn, T. (1956). Electron microscopy of the tracheal ciliated mucosa in the rat. Zeitschrift für Zellforschung und mikroskopische Anatomie, 44, 325 .

Silva, D. G. (1966). The fine structure of multivesicular cells with large microvilli in the epithelium of the mouse colon. Journal of Ultrastructure Research, 16, 693.

Sjöstrand, F. S. (1967). Electron Microscopy of Cells and Tissues, Volume 1. Academic Press, New York and London.

Requests for reprints to: Dr. I. G. S. Alexander, School of Biological Sciences, La Trobe University, Bundoora, 3083 Victoria, Australia. 